\title{
Pedro Ferreira, um escultor baiano desconhecido ${ }^{1}$
}

\section{Pedro Ferreira, an unknown sculptor from Bahia}

\author{
MARIA HeLENA OCHI FLEXOR \\ Professora da Universidade Católica de Salvador (UCSal) \\ Professora Emérita da Universidade Federal da Bahia \\ Universidade Católica do Salvador, Superintendência de Pesquisa e Pós-Graduação. \\ Avenida Anita Garigaldi, 2981, Rio Vermelho, 41940-450 - Salvador, BA \\ mariamf@ucsal.br
}

RESUMO Este trabalho é o resultado do início de um estudo sobre o escultor Pedro Ferreira. Embora seja autor de obras importantes, passa quase desapercebido na historiografia da arte baiana. Trata-se de artista que pertence ao tempo em que o neoclassicismo se impunha à cultura Ocidental, porém, ainda restavam, na Bahia, as práticas do período barroco, em especial a cópia dos grandes mestres renascentistas. Pedro Ferreira foi um desses artistas e teve como principal inspirador Murillo, da escola espanhola.

Palavras-chave Pedro Ferreira, escultura, Bahia

ABSTRACT This work is the result of a beginning study about a sculptor Pedro Ferreira. Although he was author of important workmanships, he passes almost unknown in the bahian history of art. He was an artist who lives belongs a time when the neoclassicismo was imposed to the Occidental culture, but, still remained in Bahia, the practical ones of the baroque period, in special

1 Artigo recebido em Fevereiro de 2008. Autora convidada. 
the copy of the great Renaissance masters. Pedro Ferreira was one of these artists and has inspired, as main artist, Murillo, of the Spanish school.

Keywords Pedro Ferreira, sculpture, Bahia

Quem visita a Igreja de São Francisco de Salvador, certamente há de crer que o conjunto escultórico, com características barrocas, "A visão de São Francisco", sempre esteve no alto do trono do altar-mor, tal a harmonia estética existente entre as imagens e o restante da principal capela do edifício (Fig. 1).

O conjunto "A visão de São Francisco", presente do conselheiro Francisco da Silva Pedreira à Igreja do Convento de São Francisco, foi executado por Pedro Ferreira, escultor baiano, nascido em Santo Amaro da Purificação, Bahia, em 17 de setembro de 1896.

Na década de 1920-30 foram feitas grandes reformas na Igreja franciscana, embora, muito tenha ficado para ser restaurado. Em 1926, eleito guardião, frei Philotheo Stepnam, arrecadando esmolas entre os fiéis, e com complemento de verba dada pelo Governador do Estado, Francisco Marques de Góes Calmon, tentou iniciar as obras, mas as finanças não eram suficientes. ${ }^{2}$ Pretendendo inaugurar 0 altar-mor em 1 을 de outubro daquele ano, recorreu ao recém-empossado Presidente da República, Washington Luís Pereira de Souza, ${ }^{3}$ em busca de mais recursos.

Foram os frades, e alguns mestres leigos, que promoveram e fizeram essa reforma, que durou de 1926 e 1930, estudando os estilos arquitetônicos antigos numa tentativa de conservar o monumento com seus detalhes originais. ${ }^{4}$

$\mathrm{Na}$ ficha técnica, coube a Pedro Ferreira a restauração das cariátides ${ }^{5}$ e a encarnação de imagens não designadas ${ }^{6}$. É, nesse período, que ele se ocupou do conjunto do altar-mor, ali colocado em 1930. Mesmo sem terminar a reforma total, a 2 de fevereiro desse ano, foram re-inaugurados a parte direita da nave e o altar do Sagrado Coração de J esus, ${ }^{7}$ com missa solene, às 21 horas, com pregação, coral. ${ }^{8}$

Conseguiram obter $100 \$ 000$ réis.

Que acabou dando a contribuição de 200 contos de reis.

4 Estudos feitos por frei Mathias Teves, Frei Damião e Frei Philotheo Stepnam. A direção técnica coube a Frei Prospero (logo falecido), que cuidou dos operários, todos baianos. A obra foi continuada pelo mestre Eustáquio Gomes, de Cachoeira, e o contra-mestre Arlindo do Rosário, de Cairu, Luciano Luz e J oão Paciência da Silva, marceneiros, além de vários entalhadores (A TARDE, 1 fev. 1930).

5 Tratava-se dos atlantes, erroneamente designados, então de cariátides.

6 MOREIRA, Vicente Deocleciano. História da edificação do convento e igreja de S. Francisco, In: Revista do Instituto Histórico e Geográfico Brasileiro, Rio de J aneiro, n. 86, p. 69-72, 1976-1977. p.71

7 Hoje o altar pertence ao seu orago original, São Luis, e o Sagrado Coração de J esus encontram-se no cemitério dos religiosos, na parte lateral esquerda do altar mor.

8 Nesse mesmo ano instalou-se luz elétrica na Igreja e Convento, conforme nota manuscrita feita num recorte de jornal, de 16 de agosto, afirmando que o serviço foi executado "bem e gratis pelo eng. Carrascosa". Esse 
"A visão de São Francisco" é a obra mais conhecida de Pedro Ferreira. Tem três metros e meio de altura, do pedestal ao alto da cruz, toda entalhada em cedro e policromada pelo próprio autor, usando a tradicional técnica de encarnação e pintura dos mestres setecentistas. Consta da imagem de Cristo, com o braço esquerdo preso à cruz, e São Francisco que é tocado pelo braço direito do Salvador. Os dois personagens são maiores que o tamanho natural de um homem, conforme se pode perceber na imagem em que consta o conjunto ao lado do autor.

Pelas informações da família, o artista era um profundo admirador de alguns artistas espanhóis, especialmente Bartolomé Esteban Murillo. ${ }^{9}$ Percebe-se que o conjunto teve influência direta de duas de suas pinturas principais. O Cristo se espelha na figura de São J oão Batista, da obra "O batismo de Cristo", de cerca de $1655,{ }^{10}$ e a figura de São Francisco na imagem central da obra "A cozinha dos anjos",11 de 1646., além de sua obra principal, com o mesmo título, do Museu de Belas Artes de Sevilha.

Mário Cravo J unior, artista baiano moderno e contemporâneo, testemunhou que Pedro Ferreira tinha contato com diversas publicações. ${ }^{12}$ Dizia Mario Cravo que ele próprio "paradoxalmente foi procurando técnicas e escultores que atuavam numa área tradicional e conservadora da escultura baiana de então, que recebeu os primeiros impulsos e incentivos no sentido da nova escultura internacional". ${ }^{13}$

Segundo declaração de Pedro Ferreira, dada ao Diário de Notícias, em agosto de 1930, o guardião franciscano, Frei Philotheo Stepnam, imaginou um concurso de maquetes, para a elaboração de imagem do orago da Igreja do Convento franciscano, e escreveu a Pedro Ferreira, afirmando que estava preferindo um artista nacional, visto que poderiam concorrer, também, artistas estrangeiros. Completou:

quis corresponder a esse appello e metti mãos à obra. 0 concurso aceitou a minha proposta e eu logo iniciei os trabalhos preliminares alli naquelle venerando convento, servindo de modelos dois religiosos. ${ }^{14}$

A partir de modelos e do estudo de pinturas do artista espanhol citado, Pedro Ferreira fez uma maquete, hoje de propriedade da família e, uma vez aprovada, levou dez meses, em Santo Amaro, de trabalho acurado, dia e

engenheiro foi o mesmo que instalou o mesmo serviço na Ordem Terceira de São Francisco e que descobriu a fachada original desse monumento que estava sob grossa camada de reboco.

9 Notam-se, também, influências da pintura de J usepe de Ribera. Basta contemplar o São Francisco desse pintor que data de 1643 e que se encontra no Palazzo Pitti, Florença.

$10 \mathrm{Na}$ Gemaldegalerie, Berlim.

11 Pertence ao acervo do Louvre, Paris.

12 E foi na sua oficina que Mario Cravo conheceu a obra de Ivan Metrovic, com quem estudaria nos Estados Unidos, por 1949, e que o mestre o fizera conhecer através da revista "Art of Today".

13 MESTRE dos mestres. Pedro Ferreira (Pedro Santeiro). In: Folha Salvador, Salvador, ano 1, 2000. p. 21

14 GRUPO "Visão de S. Francisco" de um artista bahiano; encommenda do Convento de S. Francisco, Diário de Notícias, Salvador, 16 ago. 1930. 
noite, para concluí-la, depois dos estudos preliminares, trabalhando o cedro, encarnando e policromando o conjunto por ele idealizado. Antes de ser entronizado no altar, o conjunto foi exposto ao público, no mesmo ano de 1930, na Chapelaria Mercury, na rua Chile, então centro comercial, social e político de Salvador, que funcionou como local de exposição por falta de galerias especializadas na cidade. 0 jornal Diário de Notícias informava que essa exposição estava "provocando grande curiosidade e elogios, sendo o facto da cidade mais em evidencia", naquele ano ${ }^{15}$, afirmando que uma multidão se sucedia diante da vitrine e completava: "Pedro Ferreira foi o mestre que operou esse milagre". O escultor contou com a apreciação popular e de mestres da Escola de Belas Artes, como Agrippiniano Barros, Olavo Baptista, Presciliano Silva, embora este último não tivesse comparecido à abertura da exposição ao público. A exposição teve repercussão até no Rio de J aneiro.

Por mais que fosse perguntado sobre o pagamento, sempre se esquivava e se referia, modestamente, as suas diminutas qualidades de artista baiano e, sobretudo, dizia que o que devia contar era que ele tinha contribuído para a remodelação "desse formidável museu de arte que é o Convento de S. Francisco", acrescentando enfaticamente "não visei lucros".

Pelo fato de ter realizado sua aprendizagem à maneira tradicional - ensino de mestre para discípulo -, e uma rápida passagem pela Escola de Belas Artes, sem ensino formal, Pedro Ferreira é considerado como um autodidata e, erroneamente, como santeiro. Estudou desenho naquela Escola, porque a cadeira de escultura estava, então, sem professor. Foi aluno de Alberto Valença, pintor, no Liceu de Artes e Ofícios.

Mostrou habilidade pela escultura desde a infância, quando copiava santinhos católicos, que sempre reproduziram imagens de artistas espanhóis do século XVII e pelos quais Pedro Ferreira se apaixonaria.

Aos 21 anos já era premiado com medalha de ouro, na exposição do Liceu de Artes e Ofícios, de 1917, com uma imagem de São Sebastião, adquirida por Teodoro Sampaio, ${ }^{16}$ de cujo destino não se tem notícia. Logo depois ganhou outra medalha de ouro, no Rio de Janeiro, em 1922, na Exposição da Comemoração do Centenário da Independência do Brasil, com um "Cristo Agonizante", que tinha em sua composição uma caveira aos pés. Esse Cristo foi adquirido por Carlos Martins Vianna, para a capela de sua propriedade, segundo consta, junto com um "Coração de J esus" e uma "Santa Terezinha", do mesmo artista. Sem se conseguir identificar 0 ano, consta que seu irmão, Caetano Ferreira, acompanhou, pelo navio

15 GRUPO "Visão de S. Francisco" de um artista bahiano; encommenda do Convento de S. Francisco, Diário de Notícias, Salvador, 16 ago. 1930.

16 Francisco Borges de Barros, Oficial de Gabinete do Governador, Diretor do Arquivo Público, comprometeu-se a comparecer à exposição para prestigia-lo. 
Itaberá, cinco obras do escultor que foram expostas na Feira Internacional de Amostras no Rio de J aneiro. ${ }^{17}$

Pedro Ferreira firmava-se, cada vez mais, como escultor. Definiu-se pela escultura aos 24 anos.

Segundo Mario Cravo J únior ${ }^{18}$ conhecia todos os processos de modelagem, cópia e reprodução em gesso, além das técnicas de manuseio da madeira ou pedra. Na descrição desse seu discípulo "era um mulato gordinho, baixo, meio-troncudo, cabelo curto e crespo, nariz achatado, olho severo, sobrancelhas espessas e muito simplório". ${ }^{19}$ E tímido.

Recebeu uma bolsa do Governo Estadual para estudarna Europa, mas, para sua profunda frustração, não pode usufruí-la. No Senador Estadual, Pedro Maia, tinha apresentado, nesse mesmo ano, um projeto àquela casa, no sentido de se conceder um auxílio de $800 \$ 000$ mensais, a fim de que 0 artista fosse aperfeiçoar seus estudos fora do País. A Revolução de 1930, que estourou no eixo Rio-São Paulo e esse projeto não pode ser concretizado. Francisco Vieira de Campos confirmava a idéia de que o Governo deveria mandá-lo aperfeiçoar-se na Europa e desafiava... "E eu quebraria a minha palheta dentro de dez annos" se Pedro Ferreira, com um aperfeiçoamento, não chegasse a ser "uma glória Universal".

Apesar desse contratempo, especializou-se em esculpir imagens sacras e tornou-se conhecido como "Pedro Santeiro", muito embora suas obras tenham se caracterizado muito mais pela monumentalidade do que por simples imagens de pequeno porte. E ficou conhecido no Sul do Pais, enquanto vivo, como representante típico da escultura nordestina.

0 artista, além de escultor, foi policromador e restaurador ${ }^{20} \mathrm{e}$ "modernizou" imagens, como a de Nossa Senhora da Graça, padroeira da Igreja do mesmo nome, considerada uma das primeiras igrejas construída no Brasil. A partir dos 13 anos aprendeu a encarnar imagens e a modelar 0 cedro com o mestre santamarense, J oão Dalmácio de Brito.

Em 1934 se propôs, apresentando orçamento, como pessoa jurídica - pela firma Pedro Ferreira \& Irmão -, para a restauração da Sacristia da Ordem 3a de São Francisco, desde o douramento do teto, retoque e envernizamento das telas dos painéis, portas, retoque do douramento dos altares, etc. que permitiu, em 11 de abril de 1935, ao bispo franciscano, D. Eduardo Herberhold, benzer o local recém-reformado. ${ }^{21}$

17 Entre 1927 e 1934 provavelmente.

18 MESTRE dos mestres. Pedro Ferreira (Pedro Santeiro). In: Folha Salvador, Salvador, ano 1, 2000, p. 21.

19 Fazia notas em qualquer pedaço de papel. Numa foto de túmulo do Campo Santo, para o qual fez pelo menos três obras, existe, no verso, uma relação de materiais, como gesso, lixa nº 2 , argolas, ao lado de café, feijão e uma lata de manteiga.

20 ARGOLO, J osé Dirson. Pedro Ferreira: escultor, policromador e restaurador. In: ABRACOR Boletim, artigos técnicos, Rio de J aneiro, ano IV, n. 2, p. 2-5, 1997.

21 ALVES, Marieta. História da Venerável Ordem Terceira da Penitência do Seráfico Pe. São Francisco da Congregação da Bahia. Bahia: Imprensa Nacional, 1948, p. 101. 
Com pouco estudo artístico, teve certo prestígio e reconhecimento profissionais, no período em que viveu, muito embora esse reconhecimento não tivesse agregado o correspondente reconhecimento econômico. Foi mestre de grandes escultores da Bahia, como Alfred Buck, Ismael de Barros e o mais conhecido deles, Mário Cravo J únior.

Tinha oficina própria e nela teve como auxiliar e aprendiz, a partir de 1945, o já referido Mário Cravo J únior. A oficina ficava na Rua Carlos Gomes, $61.22 \mathrm{Um}$ outro freqüentador da oficina, mas como amigo, era Couto Cardoso (Fig. 5), de quem Pedro Ferreira modelou um busto em gesso, depois o fundiu em bronze, acrescentando-lhe uma base de mármore, com $45 \mathrm{~cm}$. de altura. Datava de 1943.

Diferentemente do uso dos séculos XVIII e XIX, em que o escultor apenas desbastava a madeira e o pintor encarnava e policromava as imagens, Pedro Ferreira dominava todas essas técnicas, o que possibilitou, além de trabalhar suas próprias obras, restaurar várias imagens sacras de coleções dos monumentos eclesiásticos. E aventurou-se também, esporadicamente, na restauração de algumas pinturas. ${ }^{23}$

Restaurou, reencarnou e policromou várias imagens. Segundo o professore restauradorJ osé Dirson Argolo, essas obras são facilmente reconhecíveis "pelo fato de seu estilo ser influenciado pelas pinturas de imagens de gesso, que começaram a invadir o comércio local a partir do final do séc. XIX e primeiras décadas do séc. XX". Segundo o mesmo autor, as imagens policromadas por esse escultor possuem carnação delicada, mas as túnicas ou mantos têm, quase sempre, uma larga barra dourada, com motivos florais ou geométricos, bem típicos da policromia francesa. ${ }^{24}$ Como exemplos de imagens restauradas, além da imagem de Nossa Senhora da Conceição, do altar colateral da Igreja de São Francisco, ${ }^{25}$ interveio nas de Nossa Senhora da Pena, padroeira da matriz de Porto Seguro, e várias peças da matriz de Feira de Santana, como o Sagrado Coração de J esus, e outras da igreja da Piedade de Salvador. J osé Dirson Argolo, no processo de restauração da Igreja do Recolhimento de São Raimundo, identificou a sua intervenção na imagem de São Raimundo e no dossel dos retábulos, esta pelos anos de 1940. Desse profissional foram tiradas outras informações, noticiadas pelo Padre Sales Brasil, sobre a intervenção na igreja desse Recolhimento, que

22 Conseguiu, em 1930, isenção de impostos de indústria e profissão para sua oficina.

23 Tem-se notícia, dada por Argolo, que encontrou informações na Câmara Municipal de Salvador, de sua intervenção, em 1951, no retrato de Francisco Maria Sadi Carnot, do acervo da edilidade. Cf. ARGOLO, J osé Dirson. Pedro Ferreira: escultor, policromador e restaurador. In: ABRACOR Boletim, artigos técnicos, Rio de J aneiro, ano IV, n. 2, 1997, p. 5.

24 ARGOLO, J osé Dirson. Pedro Ferreira: escultor, policromador e restaurador. In: ABRACOR Boletim, artigos técnicos, Rio de J aneiro, ano IV, n. 2, p. 5, 1997.

25 Não pode ser mostrada como exemplo, porque já foi restaurada depois de sua intervenção. 
utilizou "P resciliano Silva para as sugestões, Pedro Ferreira para as famosas encarnações de imagens"... ${ }^{26}$

Esporadicamente também, como se disse, modernizou imagens. Isso se passou na década 1920-1930, quando não se desenvolvera ainda na Bahia, a noção de valor cultural e patrimonial dos objetos artísticos herdados do passado, nem tampouco se exercia a profissão de restaurador. ${ }^{27}$ Essa tarefa era praticada, segundo Argolo, por pintores, como Presciliano Silva, Robespierre de Farias, J osé Antônio da Cunha Couto, e escultores, como o próprio Pedro Ferreira. Essa intervenção incluía a reforma das imagens, mudando, muitas vezes a sua forma e a pintura, atendendo ao gosto e modismo de época.

Como foi dito, se tem notícias da reforma, ou modernização, da imagem de Nossa Senhora das Graças, por um ofício em resposta, dada pelo Diretor Regional do DPHAN, Godofredo Filho, ao Diretor Geral do Departamento do Patrimônio Histórico e Artístico Nacional, em 1954, Rodrigo Melo Franco Andrade, que investigara, a pedido deste, a autenticidade da imagem principal da Igreja da Graça. Pessoalmente, Pedro Ferreira declarou a Godofredo Filho que

\begin{abstract}
(...) a imagem do altar-mor da Graça e a velha. Logo no começo de minha carreira artística, quando ainda não tinha e em geral não se dava entre nós apreço às cois as antigas, cometi o erro, de que hoje me penitencio, de havê-la desbastado e restaurado, privando-a da rusticidade primitiva, suavizando-lhe as feições e compondo-lhe outra roupagem. Esse trabalho, realizei-o a pedido e insistência de certo Prior da Graça e, diga-se por amor à justiça e à verdade, com reprovação do falecido Abade, que se mostrou profundamente contrariado com o ocorrido. É esta, infelizmente, a verdade, frutificando meu arrependimento em jamais repetir essa falta no tratamento de outras imagens, em múltiplas oportunidades que me ofereceram. ${ }^{28}$
\end{abstract}

Tem-se apenas notícia dessa imagem modernizada. ${ }^{29}$ Segundo Frei Agostinho de Santa Maria, essa imagem era de vestir, datava do século XVII. Verifica-se que a intervenção de Pedro Ferreira, quando nada, retirouIhe volume.

Adquirindo uma certa fama, Pedro Ferreira foi chamado à cidade de Bonfim para encarnara imagem do Senhor do Bonfim, protetor da cidade do

26 ARGOLO, J osé Dirson. Pedro Ferreira: escultor, policromador e restaurador. In: ABRACOR Boletim, artigos técnicos, Rio de J aneiro, ano IV, n. 2, p. 2-5, 1997.

27 Profissão trazida para a Bahia por J. J. Rescala nos anos 1950, que tanto passou a ensinar na Escola de Belas Artes, quanto a trabalhar no Serviço de Patrimônio Histórico e Artístico Nacional, SPHAN.

28 DPHAN - 20 distrito, Ofício n. 45, de 28 de junho de 1954, enviado a Rodrigo de Melo Franco de Andrade por Godofredo Filho (cit. por ARGOLO, 1997, p. 5). Sendo informação desse documento. Pedro Ferreira não pode precisar a data exata do seu trabalho na Graça, mas supunha-se que tivesse sido feita em 1924, por ocasião das reformas feitas pelos monges beneditinos alemães, pensando-se que o prior de então fosse D. Mauro Haag que, perguntado, confirmara a necessidade dessa modernização, porque a imagem era "feia, muito bojuda" e complementando. Não existia Patrimônio, existia?

29 A ilustração está descorada, pois não se teve acesso à original. 
sertão baiano. Na oportunidade, aproveitou para "reformar" outras imagens da Igreja. Na sua estadia restaurou, também, obras de particulares.

Por outro lado, Pedro Ferreira, contradizendo, por sua vez, aos que 0 chamavam de santeiro, tomando como modelo ao mesmo Murillo, e fez duas imagens de Nossa Senhora da Conceição, uma estava na igreja matriz de São Pedro, a pedido do cônego Cristiano Muller e, uma segunda, que trabalhou na mesma época do conjunto franciscano, com cerca de 2,20m de altura, na época em que foi premiada, ainda estava de posse do artista (A TARDE, 16 ago. 1930).

Foi o escultor das imagens de Cristo. J á foi citado o "Cristo Agonizante", que pertencia ao coronel Carlos Martins Vianna. Tanto esculpiu Cristos para o interior de igrejas, quanto para logradouros públicos de cidades, como o de llhéus e de Amargosa.

O mais fantástico deles, entretanto, foi uma cópia perfeita, feita da imagem do Senhor do Bonfim, em 1941, e dado ao Estado de São Paulo, como agradecimento do presente dado pelos paulistas aos baianos, a imagem de Nossa Senhora da Aparecida ${ }^{30}$. Ficou abrigada na Igreja de Nossa Senhora da Boa Morte, enquanto não se construía uma igreja nova, pois se pretendia erguer uma paróquia ao Senhor do Bonfim na capital paulista. Consta pertencer hoje ao Santuário dos franciscanos conventuais, do Parque das Nações, em Santo André, São Paulo.

Essa imagem do Bomfim foi esculpida fielmente, medindo 2,75m de altura, ${ }^{31}$ com cruz de jacarandá, não faltando os ornatos, estes em cedro. ${ }^{32}$ Reuniu multidões, tanto em sua partida de Salvador, quanto sua chegada em São Paulo. A cópia da imagem foi benta na Basílica do Bonfim, na Bahia, sendo trasladada em procissão para a Igreja da Conceição da Praia, onde ficou exposta à visitação pública até seu embarque. Antes disso, foi promovido o encontro, as 19,15h, entre a Imagem do Bonfim com N. Sra. da Conceição, na altura do Pilar, devidamente acompanhados pelas irmandades. A imagem do Senhor do Bonfim foi transportada pelo navio Grarangua, acompanhada pelo Monsenhor Paiva Marques e padre Manoel Barbosa, comitiva organizada pelo antigo proprietário da "Era Nova", Ricardo Pereira. Aportaram no Rio de J aneiro, fazendo uma visita ao jornal "O Globo". Nesse meio tempo foi exposta e aberta a visitação pública ao navio. ${ }^{33}$

É de sua autoria um Cristo da Cidade de Cajazeiras, oferta de um paraibano, Silvino Bandeira de Melo, através de seu Governador, para ser colocado no ponto mais alto da cidade. Com 4 metros de altura, somados aos 6 metros de pedestal, o monumento alcançava 10 metros de altura.

30 A imagem de Nossa Senhora Aparecida foi trazida por peregrinos paulistas, que vinham participar do III Congresso Eucarístico Nacional, de Recife, em 1939.

31 Incluía a cruz, pois a imagem media $1,05 \mathrm{~m}$.

32 Foi inteiramente realizada por subscrição exclusivamente popular.

33 Foi, segundo cálculos da época, visitada por cerca de 4000 pessoas. 
Representava Cristo com braços abertos, como o Redentor do Rio de J aneiro e alguns dos outros Cristos do próprio Pedro Ferreira.

Consta ter feito um "Cristo Morto", inspirado em uma obra de Diego Velazquez, junto com o Cristo Agonizante, já referido, e "O Mestre", ${ }^{34}$ este último tido pela família como a obra mais perfeita do escultor. ${ }^{35}$

Também esculpiu uma "capela gótica" (indefinida), uma Conceição "de Murillo", já citada, São Vicente de Paulo, da freguesia de Santa Bárbara/BA, entre outras. Entre outras obras feitas pelo artista conta Santa Isabel. Consta que Santa Isabel, rainha de Portugal, foi uma cópia da Santa Isabel de Teixeira Lopes, e hoje está no Asilo de Santa Isabel, da Ordem Terceira de São Francisco, onde também se encontra uma Ceia de Cristo, em gesso, no refeitório, cuja maquete pertence à família e uma terceira no Abrigo São Francisco.

A Igreja de São Pedro abrigou as imagens da Conceição, inspirada em Murillo, a de Santa Mônica e de Santa Margarida Maria. Realizou outras imagens de santos, como Santa Isabel, São J osé uma das menores imagens do escultor, São Pedro. A Imaculada Conceição foi exposta com obras de outros artistas, como Alberto Valença, Presciliano Silva, Paulo Lechenmayer, cujo tema era Exposição de Arte Religiosa, na Igreja de Santo Antonio da Mouraria, em 1939. A Conceição, de Pedro Ferreira, conta como um dos trabalhos de maiores proporções já feitas em oficinas baianas. Foi apresentada ao público no Ponto da Elite, ainda sem pintura. Tomou oito meses de trabalho.

Como se costumava fazer na época, muitas de suas obras foram conhecidas pelo povo através de sua exposição em vitrines de lojas comerciais. Além da Chapelaria Mercury, Pedro Ferreira teve obras expostas na Galeria T. Dias, em São Pedro, em lojas de moda na Rua Chile, Ponto da Elite, na Avenida Sete, 51, São Pedro, em Salvador. Em 1933 expôs trabalhos no Armarinho São J osé, na praça do Comércio, de Amargoza, promovida por uma comissão local. Expôs, também na Casa Pio X, na Rua Direita, 255, em São Paulo.

Foi autor de túmulos existentes no Campo Santo. Fez bustos de pessoas ilustres: a cabeça de Ruy Barbosa, de propriedade de seu filho Pedro, 0 busto do Dr. Eurico Freitas, ex-prefeito de Mata de São J oão, cidade onde se encontra num monumento. Fez, também o busto do Governador Landulpho Alves, hoje na Escola de Agronomia, em Cruz das Almas, o busto do Dr. Pedreira Maia, fundido em bronze e que foi, também, exposto na Chapelaria Mercury.

34 Infelizmente não se conseguiu uma boa reprodução dessa imagem. Tinha 1,20 de altura e encontra-se no Abrigo do Redentor, no Rio de J aneiro.

35 Segundo informações de sua filha Célia Paes ficou no Rio de J aneiro. 
Entre todas as obras são de destacar a cabeça de Cristo, feita em madeira e de propriedade da Senhora J oselita Ferreira Pinho e o Monumento ao Soldado Desconhecido, de 1,40m de altura, em bronze, feito a pedido do Comando da Polícia Militar, das poucas esculturas com caráter leigo feita por Pedro Ferreira.

Sua última obra, inacabada, foi um Cristo Morto (1939-1940), em tamanho natural, que foi exposto numa casa de moda na Rua Chile. Passou por algum tempo no Palácio do Governo, sob a promessa de que seria adquirido pelo então Governador, Antônio Carlos Magalhães, fato que não se concretizou, voltando para a posse da família e é de propriedade de seu filho homônimo

Pedro Ferreira sempre se sentiu injustiçado. Desiludido, mostrava constantemente vontade de retornar a Santo Amaro da Purificação, sua terra natal.

Enfermo, tornou-se inativo e pouco foi lembrado por seus contemporâneos ${ }^{36}$, a exceção de um seu conterrâneo famoso, o Dr. J osé da Silveira, criador do IBIT - Instituto Baiano de Investigação do Tórax - que, já em cadeiras de rodas, com o auxílio da Professora Maria Mutti, diretora do Núcleo Cultural de Incentivo Cultural de Santo Amaro, Ihe prestou uma comovente homenagem, no dia 17 de setembro de 1996, por ocasião das comemorações do centenário de seu nascimento. Na ocasião foi feita uma exposição de seus trabalhos, com a presença da família e de representantes da sociedade santamarense.

Mas, não se pode esquecer algumas homenagens pontuais que the foram prestadas, como a feita pela poeta Maria Gonçalves Machado Torres, que chegou a dedicar-lhe o poema "Loiros ao Gênio, o artista é immortal". Como essa singela homenagem, um grupo de admiradores montou um álbum de recortes, em poder da família, ornado com graciosos desenhos coloridos a lápis de cor, mas sem indicação de datas ou outros pormenores. Mereceu também, além das palavras finais de Heitor Dias, referências de Teodoro Sampaio, Anísio Melhor e, claro, Mário Cravo J únior.

Mas, ao terminar esta investigação, volta-se ao início. Pedro Ferreira foi o autor do conjunto mais impressionante da igreja franciscana e está no lugar mais privilegiado do altar-mor. Só essa obra perpetua seu nome.

36 Faleceu no Sanatório Espanhol, a 13 de junho de 1970, sendo sepultado no Campo Santo, homenageado pelo ex-Prefeito, Dr. Heitor Dias. 


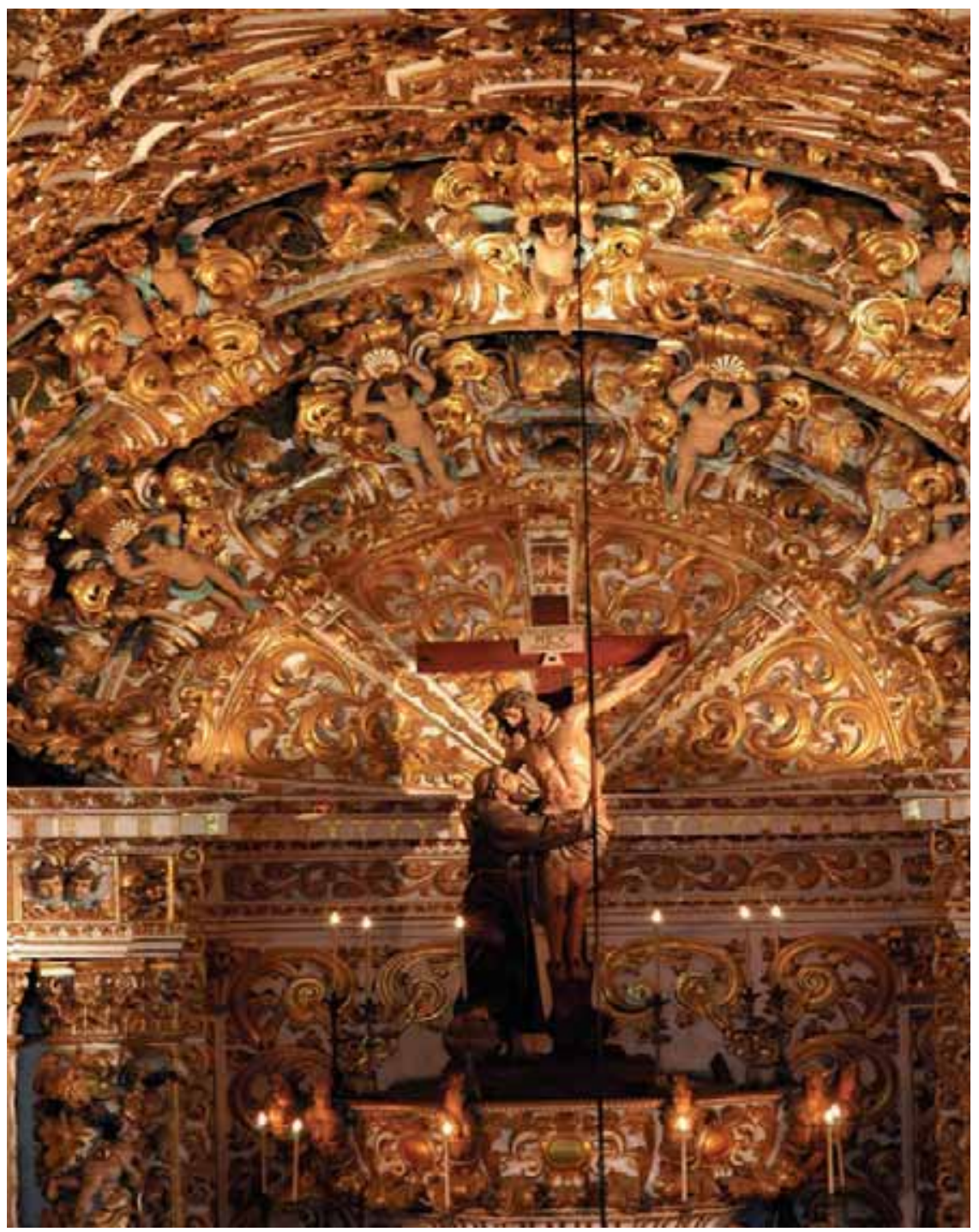

Figura 1 


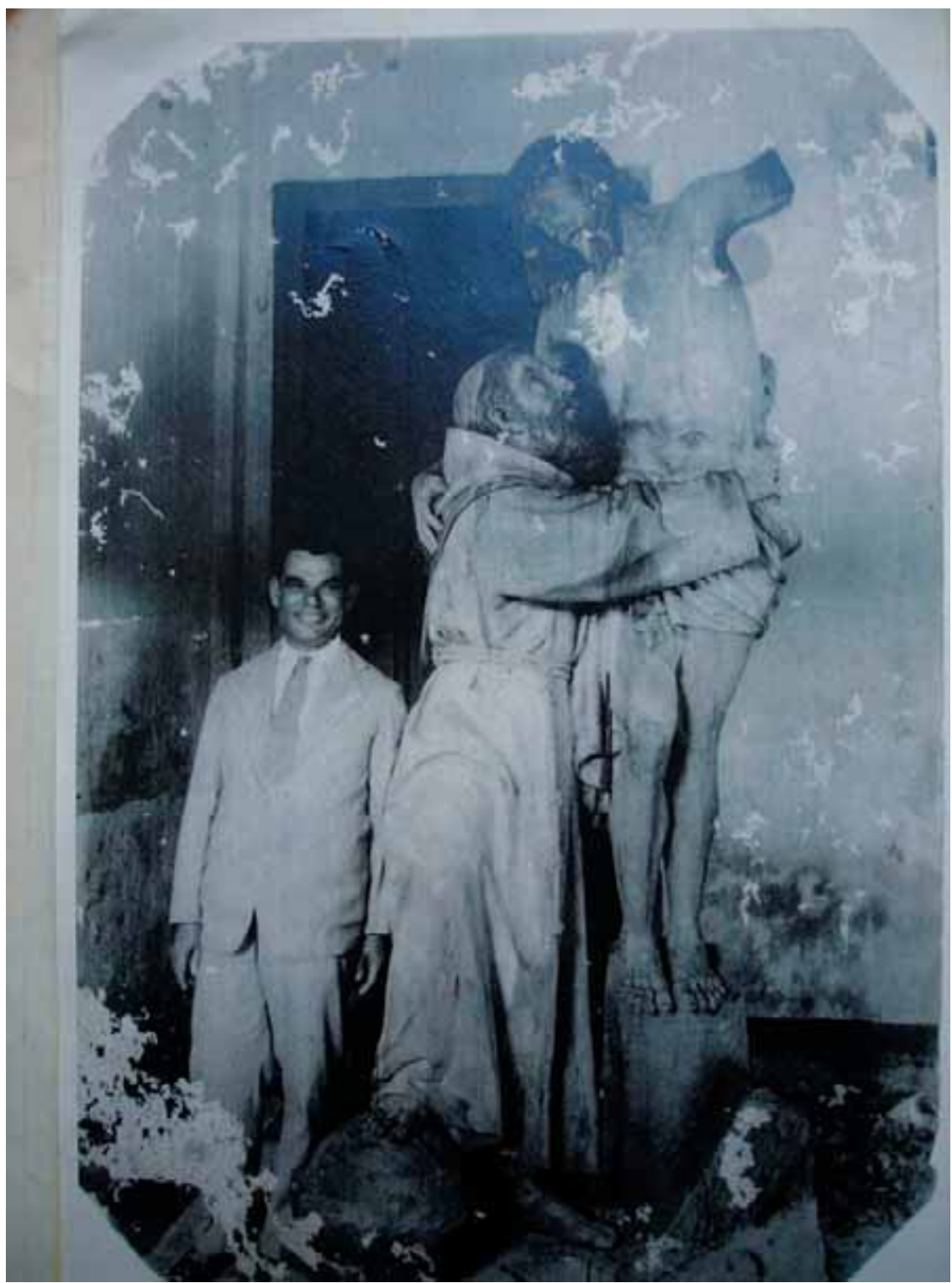

Figura 2 


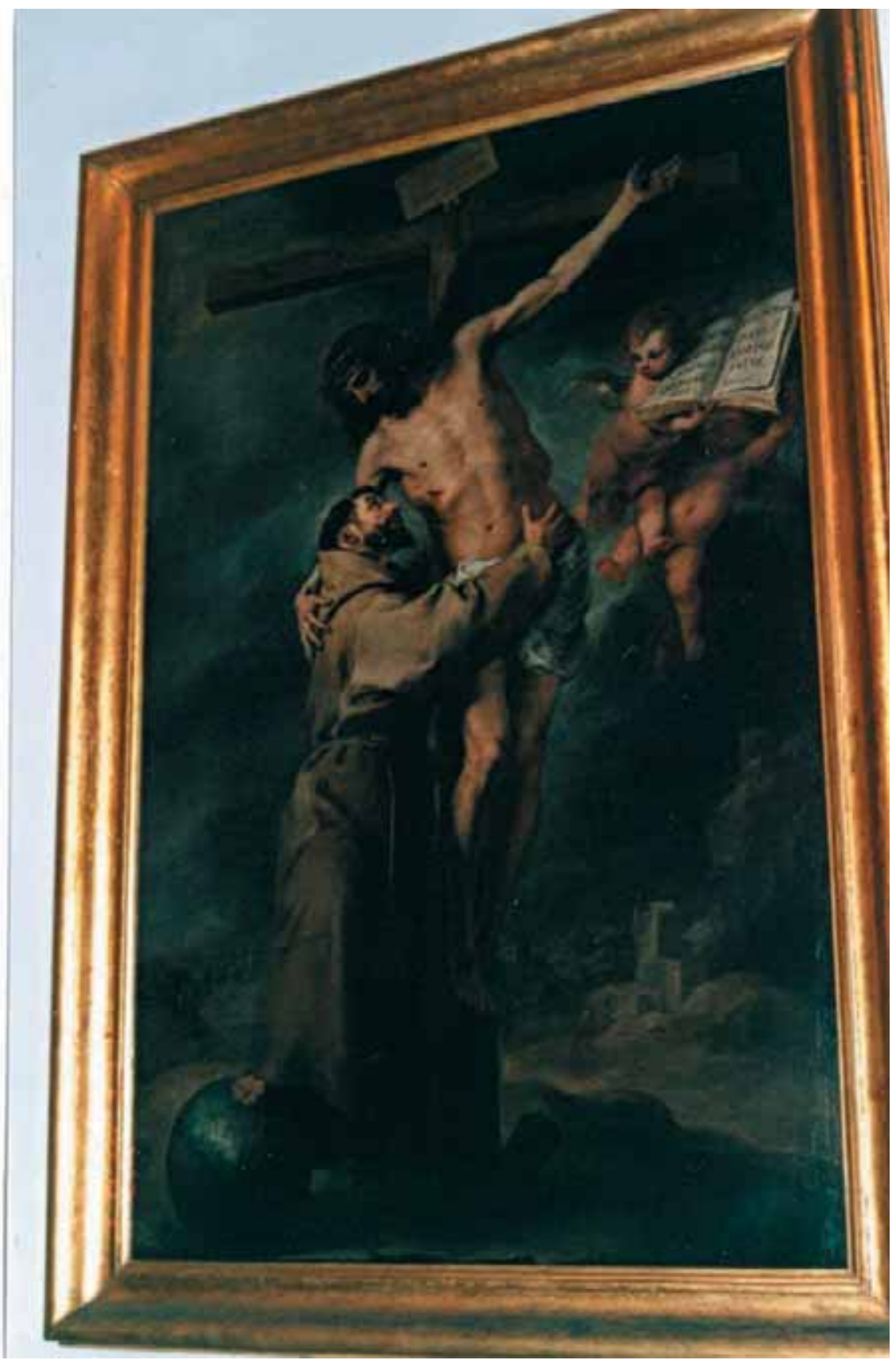

Figura 3 